ISSN 1112-9867

Available online at http://www.jfas.info

\title{
EVALUATION OF BEETROOTCHANGES DURING DRYING WITH HOT AIR BY DIGITAL IMAGES
}

\author{
F. Behrouzifar ${ }^{1, *}$, S.A. Shahidy ${ }^{2}$. \\ ${ }^{1}$ Department of Agriculture, QaemshahrBranch, Islamic Azad University, Qaemshahr, Iran \\ ${ }^{2}$ Department of Food Science and Technology, Ayatollah Amoli Branch, Islamic Azad University, \\ Amol, Iran
}

Published online: 18 June 2016

\begin{abstract}
Foods drying are an important operation in processing and increasing foodstuffs shelf life and many factors effected on products efficiency and quality during drying. Deterioration of texture structure and products color changes depends on drying method and air temperature and air rate. Drying or removing maximum water of the product conducted by the purpose of Increasing durability life and its quality. In addition, product's color must be regarded, because the most Important Factor for attracting customers and consumers oration considered as Importance of this Subject. Beetroot advised for daily consumption due to its Vitamin C and traces Such as Rubidium, Cesium for decreasing blood pressure and coronary vascular diseases and its water is the most favorable drink in the world market. The purpose of this study is creating suitable statistical model from the mentioned process and evaluation of the product color and tissue. In this study, the process by using hot air flow has been conducted for beet and its changes Investigated by the help of digital pictures and processing technique that up to now no special Investigation has been conducted. For this, used hot airflow for drying in this experiment in which Temperature and air flow rate is adjustable. The product color change has been conducted by digital Imaging.
\end{abstract}

Author Correspondence, e-mail: f.behrouzifar@gmail.com

doi: http://dx.doi.org/10.4314/jfas.8vi2s.139 
Drying process conducted for reaching confidence level by more than 3 iterations in 3 temperatures $50,60,70^{\circ} \mathrm{C}$ with 3 fan rates 300,600 and $700 \mathrm{RPM}$. In order to evaluate Home colorful parameters changes, mentioned processes have been conducted by three Iterations in determined Imaging Intervals. Finally, by using factorial statistical plan and Tookie test and Image j software, moisture changes rate, color parameters changes ( $\mathrm{L}, \mathrm{a}, \mathrm{b}$ and $\mathrm{E}$ ) evaluated, respectively. Target of this study considered as the best and most optimal drying condition by hot air for a beetroot product sample with the highest quality.

Keywords: drying with hot air, color changes, shrinkage, beetroot.

\section{INTRODUCTION}

One the oldest and the most wide processes used for preserving foodstuff against decay, is drying process which facilitates Increasing product durability time, by decreasing microbial, enzyme activities and chemical reaction rate, volume and weight loss, packaging, transportation and products storage. This process should preserve foods against decay by the leastrate of damage in products quality Index Including food value, taste, odor, color and the tissue. (Mirzamani, 2004).

Speed and air effect studied as stimuli for drying fruits. Ertekin and Yaldiz announced drying time decrease more than 50\% which Increased air flow from 60 to 80 and the rate from 1 to 3 (Ertekinand Yaldiz, 2004). Week et al, Indicated drying time decrease up to $41 \%$ by increasing air speed from $64 \%$ to $75 \%$. Transformation, volume loss and curve Increase in many materials resulted in water loss and negative confirmation of consumer. (Leon \& Merry, 2006) texture structure deterioration and product color changes depend on drying method and air temperature and rate.)

Beet is the most favorable fruit and its water considered ad the most favorable drinks in the world market. This fruit due to its Vitamin $\mathrm{C}$ and traces such as Rubidium and Cesium welcomed by the public.

So that it is necessary to consume it daily for decreasing blood pressure and coronaryvascular diseases. Foods tuffs drying is and Important, old and very useful methods in foodstuff process, (Kumar 2014). Drying caused foodstuff preservation, weight loss and product volume and finally, facilitation in storage transportation, easy use of dried product. (Fatemi, 2002). Today, one the main reason of drying is diversity of consumed products.

Rutti Found out in high rates of the air, internal resistance of transportation Mechanism controlled in these products. According to his Inferences, speed is the only factor affected on the products shrinkage and air temperature has not so much effect. Package drying differed 
depending on the condition and functions over the product. It is tried in this study to use a Machine with less damage on the tissue, shape, foodstuff color and studied schematically. This article studied beet drying by using hot air dryer and also color changes of this product selected following temperature and speed, (Davies, 2009).

\section{Materials and Methods}

While In this study drying with hot air targeted in adjustable condition for air flow rate and different temperatures and if drying machine is not available in the market such specifications, this machine exclusively built for this test, containing dryer container of the product sample, Inter container light, LED adjustable display screens around the fan and temperature adjustment, air flow production system, heating system and imaging system used for drying beet layers, (Figure 1).

Atmosphere air entered dryer container through radial fan by adjusting fan flow in the range of 300 to $1000 \mathrm{cycle} /$ minute by passing the board producing adjustable heat in the 30 to $80^{\circ} \mathrm{C}$ spectrum. Total air flow and system heat adjusted through digital control board based on hypothesis and test rates with fan cycle in three stages of 700, 600 and 500 cycle/ Min and container temperature in three temperatures 50,60 , and $70^{\circ} \mathrm{C}$.In order to perform this test, it is necessary to treat beet samples at first for (1) hour in boiling manner and spend 1 hour for cooling it and then by using cutter Machine cut them by $0 / 5 \mathrm{~cm}$ thickness then prepare the cat samples by a frame with $4 / 1 \mathrm{~cm}$ diameter in equal sizes. Before starting drying performance, required to balance all prepared samples by means of digital scale in $0 / 01 \mathrm{~g}$ accuracy.

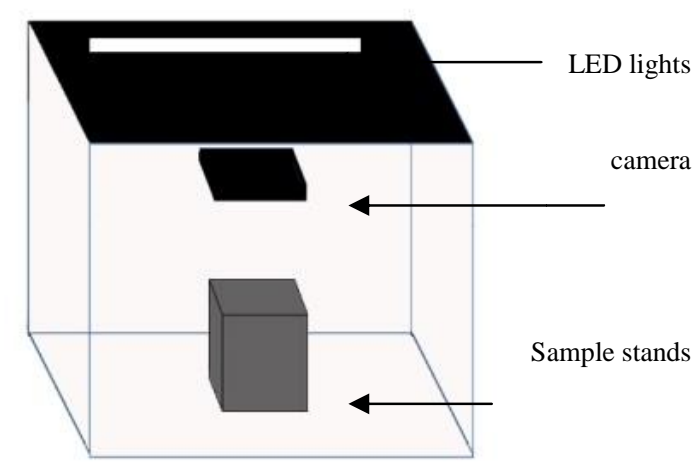

Fig.2. Photography box

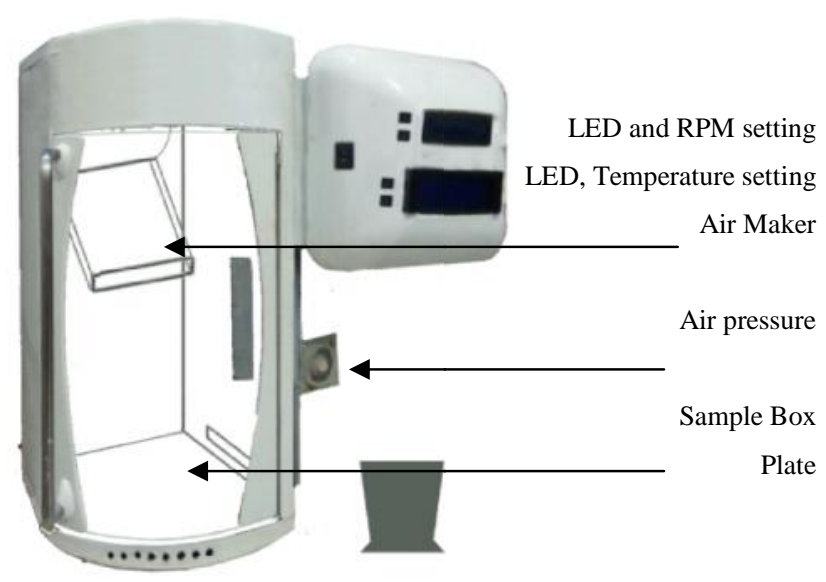

Fig.1. Schematic of Dryer Machine 
And note all the numbers by coding samples for any test in the sheets. Then, determine and measure color changes by using Insolated Imaging system relating to before and after situation recording of the samples. So that, this system composed of a cubic box with internal black color $40 \times 80 \times 80 \mathrm{~cm}$, dimensions and 4 fluorescent lamps with equal brightness equipped with SONY camera Image Source Model DSC- WX7 and 16/2 megapixel resolution which adjusted by hand and prepared in standard $20 \mathrm{~cm}$ distance from container floor, (Figure 2).

After balancing performance started by Imaging any sample drying stage with adjusting the sample and samples drying accurate time balanced in the last stage in few time Intervals while the process is not damaged. Finally, if two time Intervals are the same, it will indicate sample drying and dry material.

\section{DISCUSSION AND CONCLUSION}

\section{Drying:}

Following results about time and condition of drying beet samples showed for all parametric space. High temperature and fans higher cycle decreased drying time considerably and discussed and concluded in this regard. In comparison to obtained results from Vals and et al studies, found that air rate has very high effects on drying result more than expected by previous authors and maximum air rate during drying flow length related to adjusted temperature amount which had maximum effect on drying process and this rate is considerable in applying higher speed.

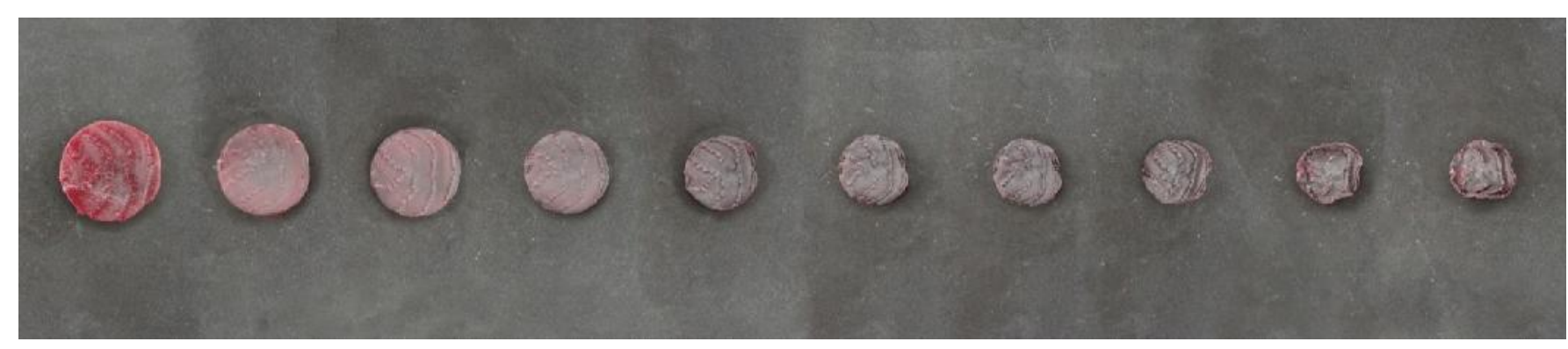

Fig.2. Step by step of beetroot drying 


\section{Color Evaluation:}

Color is a qualitative important factor for dried products which effected on consumed products. Using Digital camera considered as a valuable method with a speed for Measuring color changes in products drying process such as beet products. Product color changes had direct relation with its pigments existence of pigments in the food pruned to changes and distortion resulted from the heat. This damaged it.

Color results reported as L, a, b factors that L factor Indicated transparency- factor a showed redness- sample greenness and factor b showed samples yellow and blue color. According to the air rate graph during drying showed considerable effects on product quality in the whole study, also air rate Increase synchronously with air temperature Increase caused solution solid material exit from the fruit and this product over the surface caused severe color changes resulted in factor a Increase and then brownish color appeared due to existing anthocyanin's deterioration in the beet in high temperature and high fan cycle.

Also, must regard that low fan cycle and low temperature followed by drying time rising but less color deterioration observed by two factors and according to the following table, temperature and speed are factors.

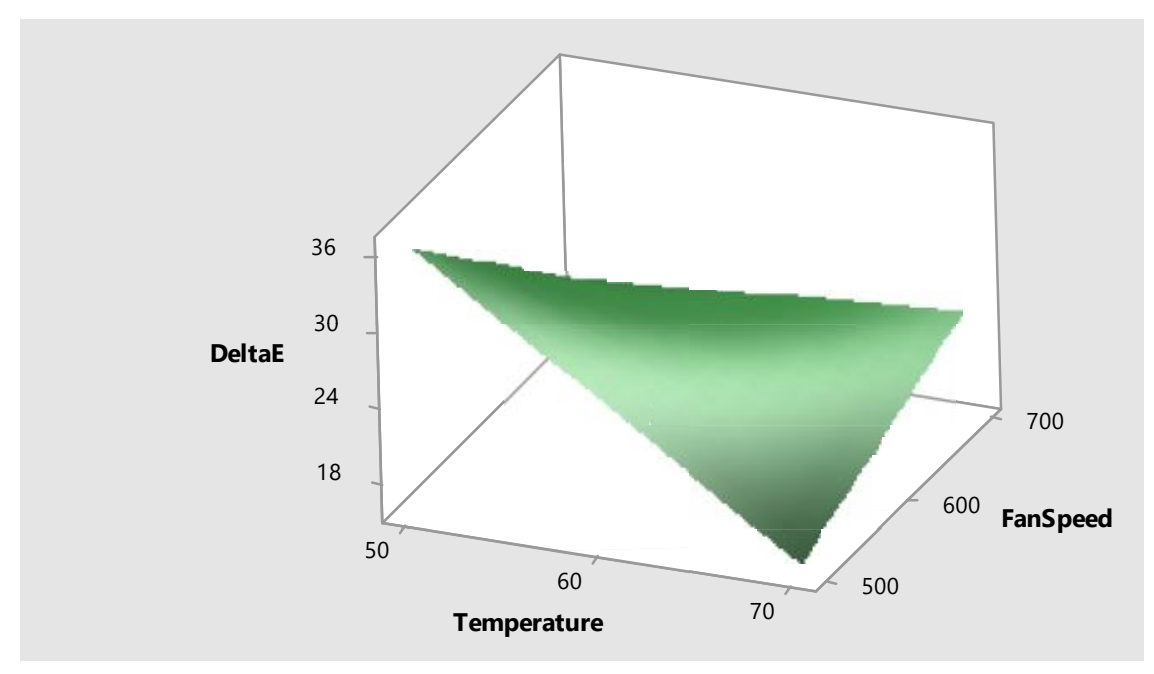

Fig.3. The interaction between the fan speed and temperature on color changes 


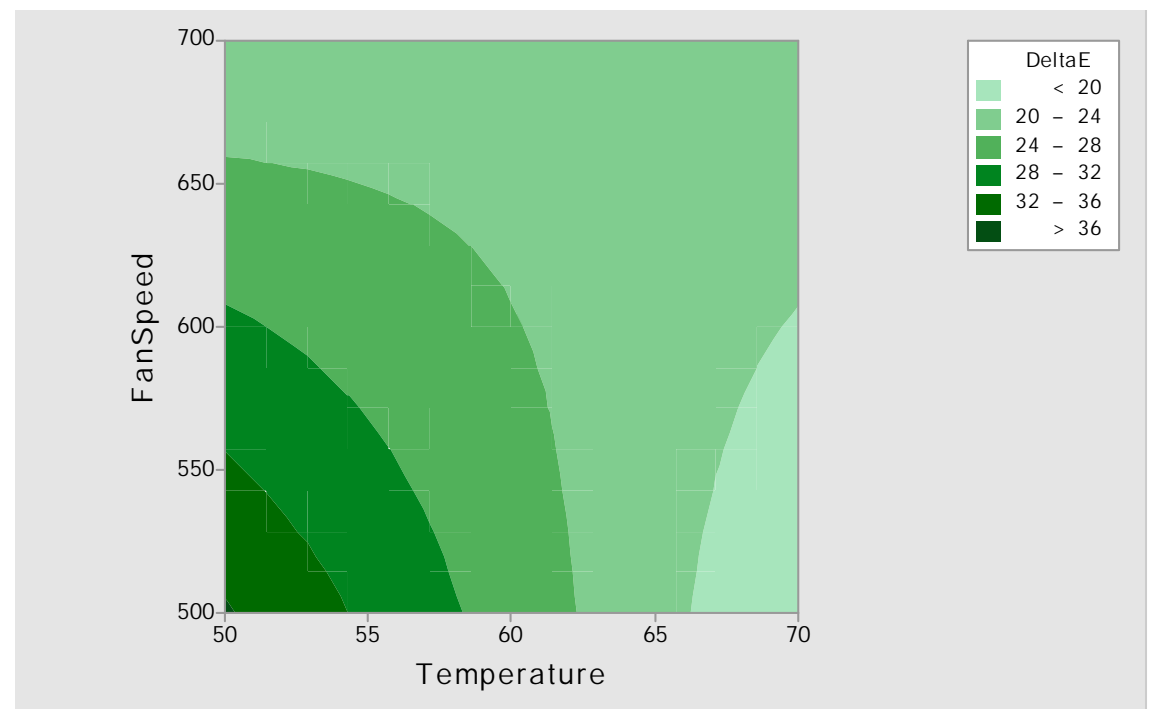

Fig.4. The interaction between the fan speed and temperature on color changes

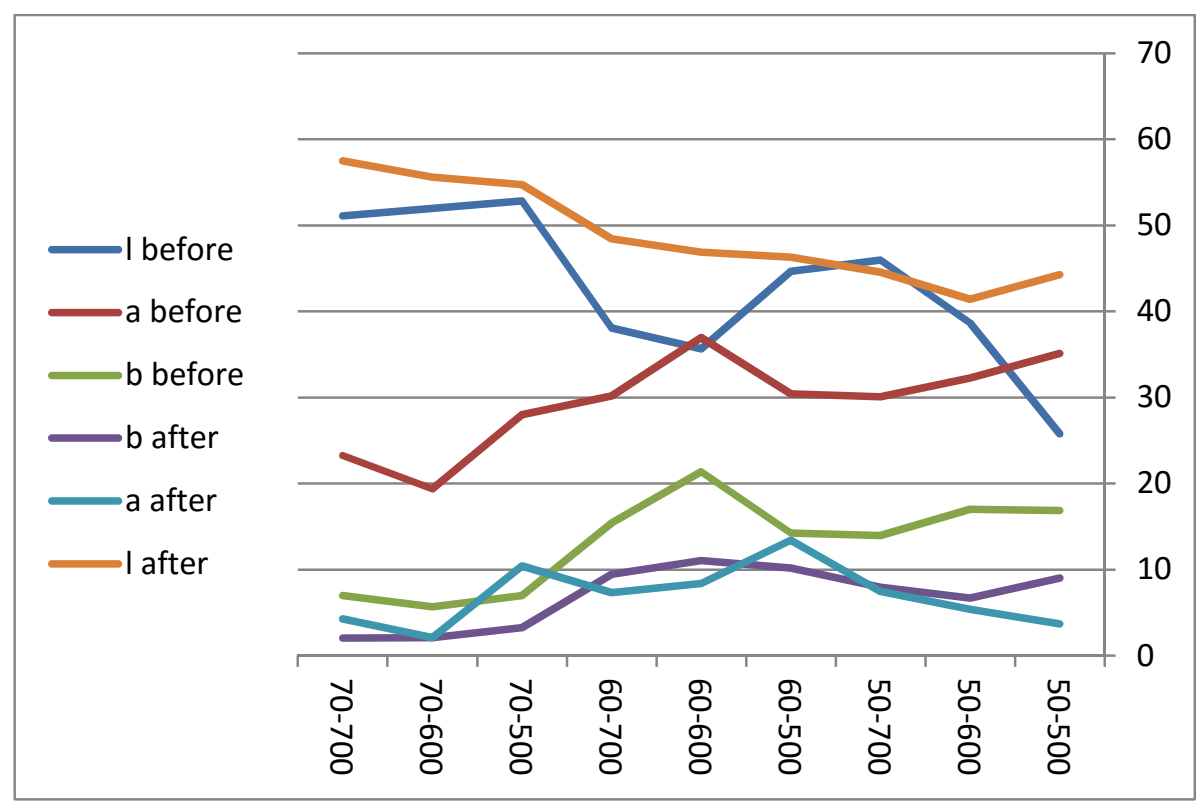

Fig.5. Color parameters in fan speeds and temperatures 


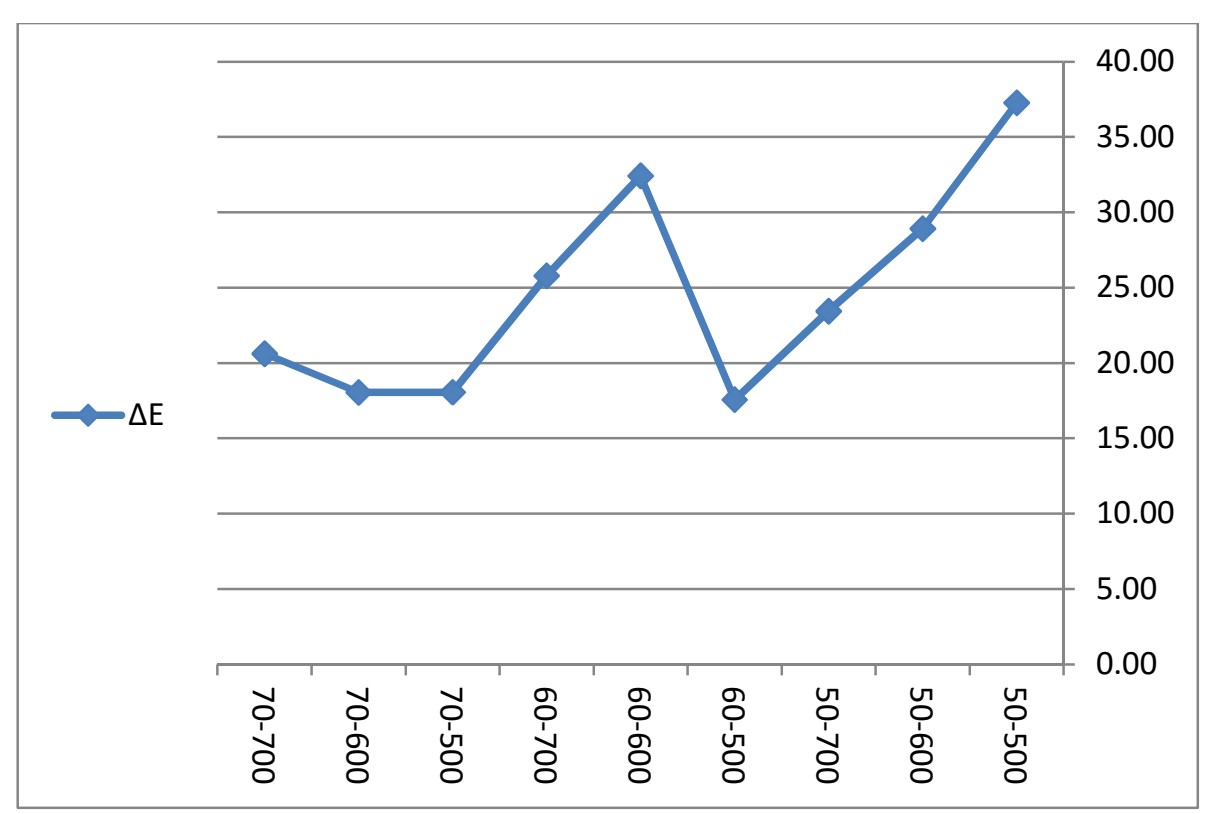

Fig.6. E in fan speeds and temperatures

\section{Shrinkage:}

That caused shrinkage in products. High shrinkage in products influenced the products quality negatively and Volume loss and stiffness Increase affected negatively on products.

Shrinkage degree and cellular tissue structure deterioration depend on drying method, fan rate and air temperature. Ratti et al. reported that in high rates of the air, internal resistance controls transportation Mechanisms in the products. (Ratti et al, 1994)

Resulted graphs from measuring shrinkage rate after the process with different condition with three Iterations will be as follows: 


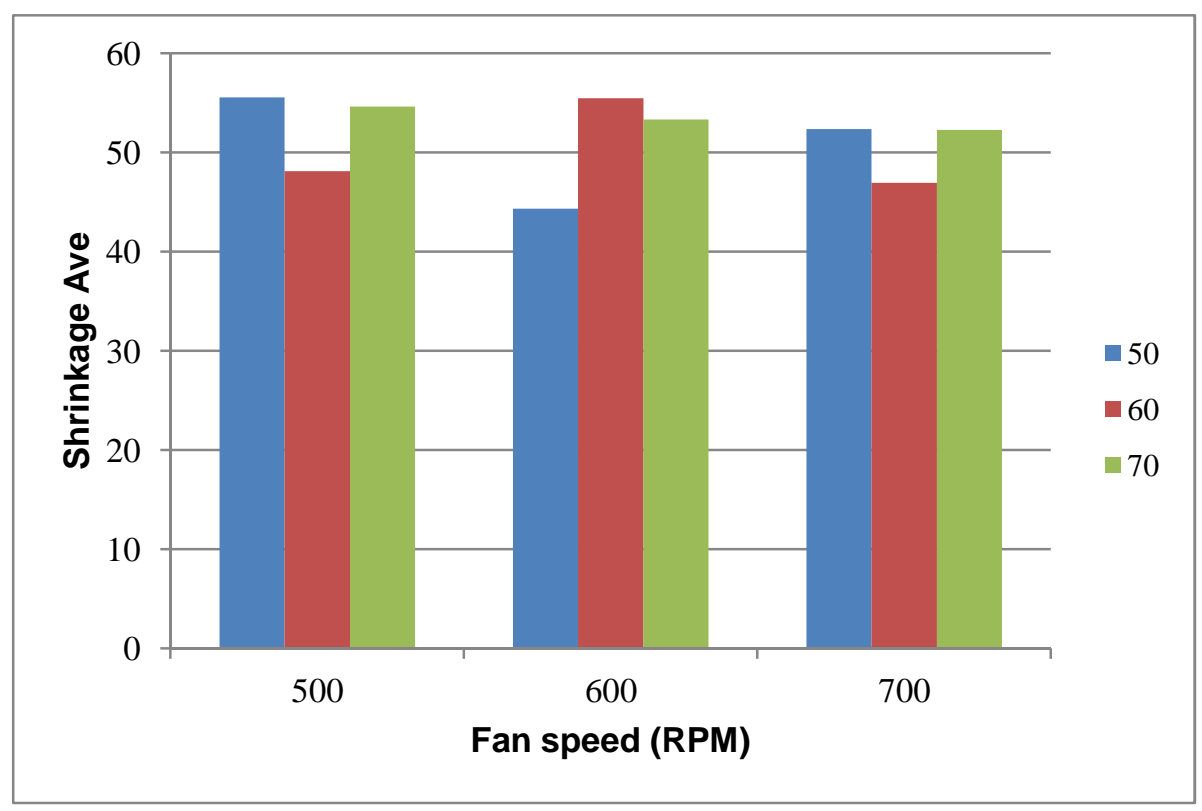

Fig.7. Shrinkages in fan speeds and temperatures

Also observed that dryer rate caused discoloration time Increase. Also, fan cycle and speed rising, increased moisture exit rate. This result adapted with strumillo and kurda (1996) and Hatamipour et al 1987 theories. And it is probably due to usage of the same dryer means hot air dryer and there is approximately the same tissue between two fruits tissue.

According to (Aydin and Kaya, 2007) studies and results obtained from beet drying trend, specified that between drying time and drying temperature, there is a significant relation. Also, moisture exit from the fruit tissue Increased with high temperature and at last decreased when major rate of moisture loosed.

In addition, drying time is short in the beginning of time of sample drying and become longer in the end of process. Vaporization speed Increased with temperature rising.

These results were the same with (Aydin and Kaya, 2007) studies on blueberry and according to Lopez writing related the longest time to the $50^{\circ} \mathrm{C}$ temperature and the shortest time to $70^{\circ} \mathrm{C}$ temperature. This similarity is probably due to drying condition or transference of mass and moisture from the product surface.

During drying, existing viscoelastic webs inside the material, created in void spaces which shrank due to vaporization. Finally, this process caused the product shrinkage and contraction (Mohtasebi et al, 2003)

Shrinkage phenomenon effected on Influence coefficient and resulted in mass and temperature transference area. (Karim and Hawlader 2005) and (Hima et al, 2002) pores and 
shrinkage creation depend on all types of external pressure and moisture transference. And also solid matrix Inflexibility could effect on pod stiffness and its permeability- (Eren- 2008)

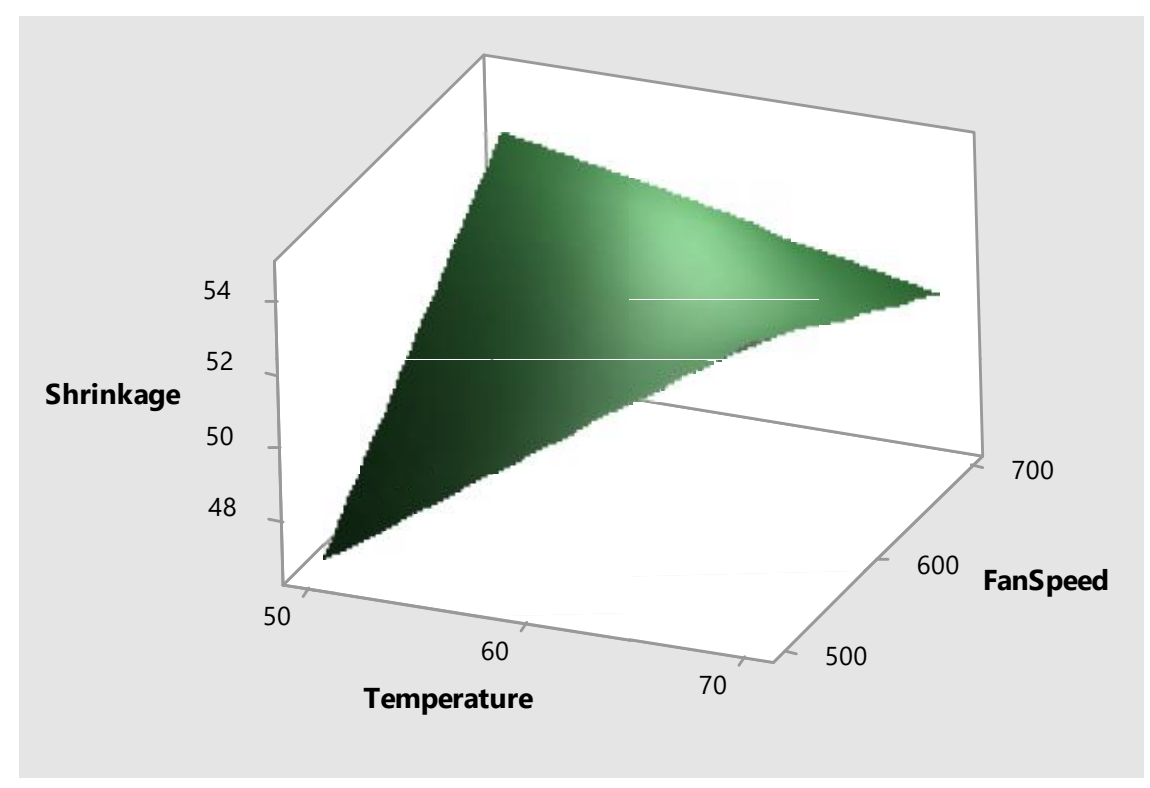

Fig.8. The interaction between the fan speed and temperature on Shrinkages

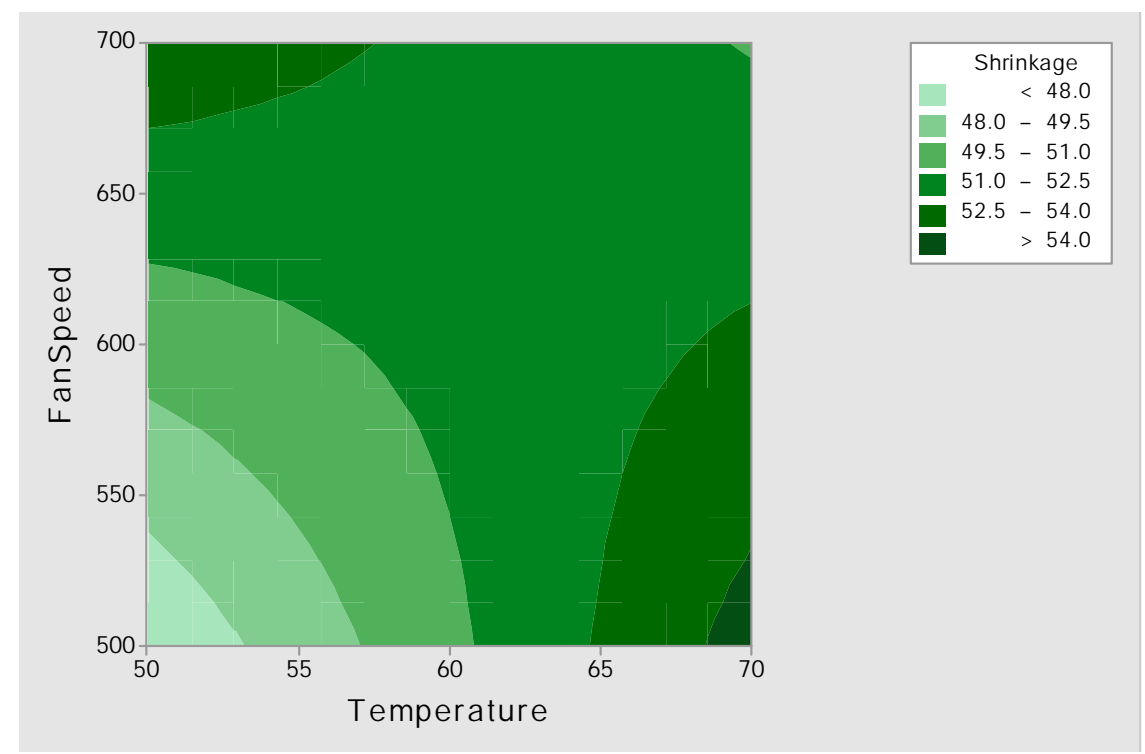

Fig.9. The interaction between the fan speed and temperature on Shrinkages

\section{CONCLUSIONS}

This study shown the using a digital camera and process images with software was successfully applied as a fast and reliable method for measurement of color changes and 
shrinkage during the drying with hot air process of beetroot. Good correlations were obtained for all parameters investigated. In this form, the system is not suitable for measurement of absolute values but can be used to provide information on relative changes during the drying process. The influence of deformation of the beetroot samples and reflections may disturb the image acquisition. For the increase of quality criteria investigated, strong interdependences of the factors studied were found. This result shows that it is important to consider all three factors investigated when optimizing the drying process. Air velocity has been shown to have a significant influence on beetroot quality throughout the investigated parameter space affecting all criteria. This may suggest that an increase in air velocity is an alternative to increasing air temperature when attempting to reduce processing time without damaging the beetroot quality. Further research has to be accomplishing to obtain more information on the overall tissue by increasing the number of individual measurements. Finding ways for a more holistic nomination of beetroot quality than the methods that are already established in scientific research and industriesare regarded as very important. These methods will need to combine more information and processes on the quality-defining aspects of the end product, for which a combination of available non-invasive techniques represents a possible solution.

\section{REFERENCES}

[1] Barbara Sturm, Werner C. Hofacker, Oliver Hensel. Optimizing the Drying Parameters for Hot-Air-Drried Apples. Drying Technology 2012, 1570-1582

[2] Davies, E.R. The application of machine vision to food and agriculture. The Imaging Science Journal 2009, 57(4), 197-217

[3] Eertekin.C,O.Yaldiz. Drying of eggplant and selection of a suitable thin layer drying model, Journal of food Engineering, 2004, 63, 349-360.

[4] Karim, M. A. and M. N. A. Hawlader. Drying characteristics of banana: theoretical modelling and experimental validation. J. Food Eng., 2005, 70, 35-45

[5] Kumar, Chandan, M. A. Karim, and Mohammad UH Joardder. Intermittent drying of food products: A critical review. Journal of Food Engineering, 2014, 121, 48-57.

[6] Ismail Eren, BanuKoc, FigenKaymakErtekin. Modelling bulk density, porosity and shrinkage of quince during drying, The effect of drying method. Journal of food engineering, 2008, 85, 340-349

[7] Leon, Kevin.; Merry, D.; overreaching, F.; Leon, J. Color measurement in L*a*b* units from RGB digital images. Food Research International 2006, 39(10), 1084-109 
[8] Lima,A.G.B; Queiroz,M.R; Nebra,S.A. simultaneous moisture transport and shrinkage during drying solids with ellipsoidal configuration. Chemical engineering journal 2002, 86 (12), 85-93.

[9] Mirzamani.S, 2004.Apple drying process by hot air and the study of some physicochemical parameters affecting it. Master's thesis, Islamic Azad University of Sabzevar Mohtasebi, S. Ebrahimi, A. Rafiei, SH, Nassiri. E, Hisseinpour. S, 2013, Effect of different factors affecting the rate of shrinkage during the drying banana thin sheets using Response Surface Methodology, Scientific Journal of Agriculture, 2013, 36(2), 213.

[10] OrhanAydin, Ahmet Kaya, CevdetDemirtas, MithatAkgun. An experimental study on the drying kinetics of quince. Desalination, 2007, 212, 328-343

[11] Pedresch, F.; Leon, J.; Domingo, M.; Moyano, P. Development of a computer vision system to measure the colour of potato chips. Food research international, 2006, 39(10), 10921098

[12] Ratti, C. 1994. Shrinkage during of food stuffs. Journal of Food Engineering, 23: 91-105. Strumillo, S., Kudra, T., Drying : Principles, applications and design, (1996), Gordon \& Breach science publishers, USA

[13] Vadivambal,R.;Kayas,D.S. Applications of thermal imaging in agriculture and food industry, a review. Food and Bioprocess Engineering, 2010, 4(2), 186-199.

\section{How to cite this article:}

Behrouzifar F, Shahidy SA. Evaluation of beetroot changes during drying with hot air by digital images. J. Fundam. Appl. Sci., 2016, 8(2S), 860-870. 